\title{
SOME PHYSICS ISSUES OF CARBON STRIPPING FOILS *
}

\author{
W. Chou\#, J. Lackey, Z. Tang, P. Yoon, Fermilab, Batavia, Illinois, USA \\ M. Kostin, NSCL, East Lansing, Michigan, USA
}

\section{Abstract}

Carbon foils are widely used in charge-exchange injection in high intensity hadron accelerators. There are a number of physics issues associated with the use of carbon foils, including stripping efficiency, energy deposition and foil lifetime (temperature rise, mechanical stress and buckling, etc.). This paper will give a brief discussion of these issues.

\section{INTRODUCTION}

Fermilab, like many other laboratories, employs a charge-exchange method during the injection of particle beams from the Linac to the Booster. The $\mathrm{H}^{-}$ions are accelerated to $400 \mathrm{MeV}$ in the Linac and pass through a thin carbon foil when entering the Booster. The foil strips two electrons from each ion and converts the ions from $\mathrm{H}^{-}$ to $\mathrm{H}^{+}$, which are then accelerated to $8 \mathrm{GeV}$ in the Booster. Figure 1 shows the foil changer in the Booster and a used carbon foil.

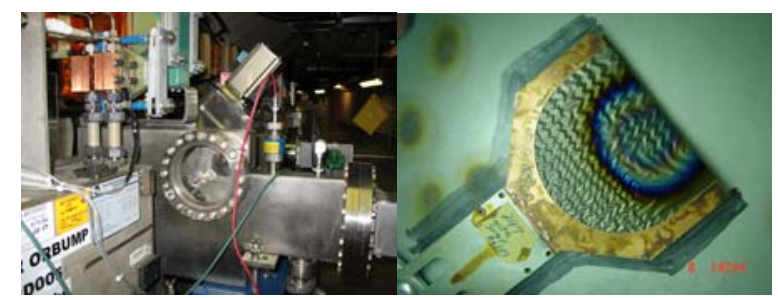

Figure 1: Left - Booster foil changer, right - a used foil.

At present Fermilab is considering to replace the Linac and Booster by a superconducting RF linac, nicknamed "Proton Driver" [1]. This machine will accelerate $\mathrm{H}^{-}$ions up to $8 \mathrm{GeV}$ with a total power of $0.5 \mathrm{MW}$. These $\mathrm{H}^{-}$ions will then be stripped to protons in foils and injected into the $120 \mathrm{GeV}$ Main Injector (MI) for mass production of neutrinos aimed at a detector (MINOS) in mine shaft in Soudan, Minnesota to study neutrino oscillations.

When the energy of $\mathrm{H}^{-}$ions increases, it becomes more difficult to convert $\mathrm{H}^{-}$to $\mathrm{H}^{+}$in foils because the interaction cross sections are decreased at higher energies. One obvious way to compensate for the cross section reduction is to use thicker foils. Unfortunately this approach has limitations since it leads to more severe foil heating and stress, which would reduce the foil lifetime. This problem is especially important for high intensity hadron accelerators such as the MI upgrade, SNS and JPARC, in which minimal beam loss and proper foil lifetime are essential to machine operation.

\footnotetext{
* Work supported by the U.S. Department of Energy under Contract No. DE-AC02-07CH11359.

\#chou@fnal.gov
}

\section{STRIPPING EFFICIENCY}

\section{Theory on Cross Section}

The theoretical approach for calculating the collisional electron-detachment cross section for negative hydrogen ions incident on hydrogen, helium, oxygen, nitrogen and other gas targets can be found in numerous publications. Here we will use the results from Gillespie in Refs. [2-5]. This method is an extension of Bethe's theory. It employs the sum-rule technique in the Born approximation to sum over all excited final states of the $\mathrm{H}^{-}$ion for calculating the total electron loss cross section. This method is particularly useful in our case because $\mathrm{H}^{-}$ion has no bound excited states. The total electron loss cross section can be expressed as:

$\left(\sigma_{-1,0}+\sigma_{-1,1}\right)=8 \pi a_{0}^{2}\left(\frac{\alpha^{2}}{\beta^{2}}\right) \sum_{n \neq 0} \sum_{m}\left[I_{n m}-J_{n m}\left(\beta^{2}\right)-K_{n m}\left(\beta^{2}\right)\right]$

in which $\sigma_{-1,0}$ is the cross section from $\mathrm{H}^{-}$to $\mathrm{H}^{0}, \sigma_{-1,1}$ from $\mathrm{H}^{-}$to $\mathrm{H}^{+}, n$ the final states of $\mathrm{H}^{-}, m$ the final states of the target atom, $a_{0}$ the Bohr radius, $\alpha$ the fine structure constant, $\beta$ the relativistic factor, $I_{n m,} J_{n m}$ and $K_{n m}$ integrals. The first integral $I_{n m}$ is the asymptotic (highenergy) leading order contribution to the cross section and is independent of the incident velocity. The second and third integrals $\left(J_{n m}\right.$ and $\left.K_{n m}\right)$ are the next order correction terms for low energies.

\section{Energy Scaling}

It is interesting to note that the physics governing the foil stripping and residual gas stripping is the same. It is only because of the enormous difference in atom density between foil and residual gas that the $\mathrm{H}^{-}$ions can travel thousands of meters in the transport line free of stripping and, suddenly, be fully stripped by a foil in a distance of a few $\mu \mathrm{m}$ !

When $\mathrm{H}^{-}$ion energy increases, the cross section decreases as $1 / \beta^{2}$ as shown in the above equation. As a consequence, the stripping efficiency decreases. This is a major concern for high energy (e.g. $8 \mathrm{GeV}) \mathrm{H}^{-}$injection, because low efficiency implies high injection losses.

Table 1: $\mathrm{H}^{-}$Stripping Cross Section (unit $10^{-18} \mathrm{~cm}^{2}$ )

\begin{tabular}{|l|l|l|l|l|}
\hline & $\begin{array}{l}800 \mathrm{MeV} \\
\text { (meas.) }\end{array}$ & $\begin{array}{l}200 \mathrm{MeV} \\
\text { (meas.) }\end{array}$ & $\begin{array}{l}200 \mathrm{MeV} \\
\text { (scaled) }\end{array}$ & $\begin{array}{l}8 \mathrm{GeV} \\
\text { (scaled) }\end{array}$ \\
\hline$\sigma_{-1,0}$ & $\begin{array}{l}0.676 \pm \\
0.009\end{array}$ & $\begin{array}{l}1.56 \pm \\
0.14\end{array}$ & 1.49 & 0.484 \\
\hline$\sigma_{0,1}$ & $\begin{array}{l}0.264 \pm \\
0.005\end{array}$ & $\begin{array}{l}0.60 \pm \\
0.10\end{array}$ & 0.584 & 0.189 \\
\hline$\sigma_{-1,1}$ & $0.012 \pm$ & $-0.08 \pm$ & 0.026 & 0.0086 \\
& 0.006 & 0.13 & & \\
\hline
\end{tabular}


Several cross section measurements of $\mathrm{H}^{-}$ion incident on carbon foil at different energies have been reported [611]. Based on the data and energy scaling formula, one can estimate the cross section at higher energies as listed in Table 1. The scaling uses $800 \mathrm{MeV}$ data. It is seen that the measured $200 \mathrm{MeV}$ data agrees well with the cross section obtained from scaling, a proof that this scaling works.

\section{FOIL LIFTIME}

\section{Energy Deposition}

The energy loss of moderately relativistic particles other than electrons in matter is primarily due to ionization and atomic excitation. For $8 \mathrm{GeV}$ protons incident on a carbon foil, the stopping power $|\mathrm{d} E / \mathrm{d} z|=$ $1.847 \mathrm{MeV} /\left(\mathrm{g} / \mathrm{cm}^{2}\right)$ [12]. When an electron travels together with an $8 \mathrm{GeV}$ proton, its kinetic energy is 4.357 $\mathrm{MeV}$. The stopping power is $1.71 \mathrm{MeV} /\left(\mathrm{g} / \mathrm{cm}^{2}\right)$ [13]. For a foil of a thickness of $300 \mu \mathrm{g} / \mathrm{cm}^{2}$, the energy deposition is $554 \mathrm{eV}$ by one proton and $513 \mathrm{eV}$ by one electron. Both are remarkably similar. However, while the electrons would hit the foil only once, the protons would hit it multiple times during multi-turn injection. Take the Fermilab Proton Driver as an example. The average number of hits for each proton is 4.4 (90-turn or $1 \mathrm{~ms}$ injection) or 15.9 (270-turn or $3 \mathrm{~ms}$ injection). The total energy deposition on the foil during injection is, respectively, $0.1833 \mathrm{~J}$ (by protons, 90-turn), $0.6625 \mathrm{~J}$ (by protons, 270-turn), and $0.07715 \mathrm{~J}$ (by electrons). The injection interval is $1.5 \mathrm{sec}$. It uses two $300 \mu \mathrm{g} / \mathrm{cm}^{2}$ foils, $40 \mathrm{~cm}$ apart, each of the size $12 \mathrm{~mm} \times 12 \mathrm{~mm}$.

\section{Thermal Analysis using MARS}

The space distributions of particles for each turn were simulated by the code STRUCT [14]. The results were then fed into the code MARS [15] where interactions of the protons and electrons in the carbon foils were simulated and the deposited energy calculated. The specific heat of carbon foils is $0.165 \mathrm{cal} / \mathrm{g}-\mathrm{K}$ or 0.6908 $\mathrm{J} / \mathrm{g}-\mathrm{K}$ at room temperature and is treated as a function of temperature in the calculation because it rises in a hot foil. Table 2 lists the peak energy deposition and peak instantaneous temperature rise due to heating by protons and electrons for each injection scheme. Figure 2 shows the temperature distribution on the two foils.

Table 2: Energy Deposition and Temperature Rise (MARS)

\begin{tabular}{|c|l|l|l|l|}
\hline $\begin{array}{c}\text { Injection } \\
\text { Turns }\end{array}$ & $\begin{array}{l}\text { Peak E } \\
\text { Deposit } \\
\text { Foil 1 } \\
(\mathrm{J} / \mathrm{g})\end{array}$ & $\begin{array}{l}\text { Peak T } \\
\text { Rise } \\
\text { Foil 1 } \\
(\mathrm{K})\end{array}$ & $\begin{array}{l}\text { Peak E } \\
\text { Deposit } \\
\text { Foil 2 } \\
(\mathrm{J} / \mathrm{g})\end{array}$ & $\begin{array}{l}\text { Peak T } \\
\text { Rise } \\
\text { Foil 2 } \\
(\mathrm{K})\end{array}$ \\
\hline 90 & $\begin{array}{l}3621 \pm \\
128\end{array}$ & $\begin{array}{l}1991 \pm \\
70\end{array}$ & $\begin{array}{l}2502 \pm \\
141\end{array}$ & $\begin{array}{l}1470 \pm \\
83\end{array}$ \\
\hline 270 & $6616 \pm$ & $3358 \pm$ & $6639 \pm$ & $\begin{array}{l}3368 \pm \\
248\end{array}$ \\
& 459 & 233 & 488 & 248 \\
\hline
\end{tabular}
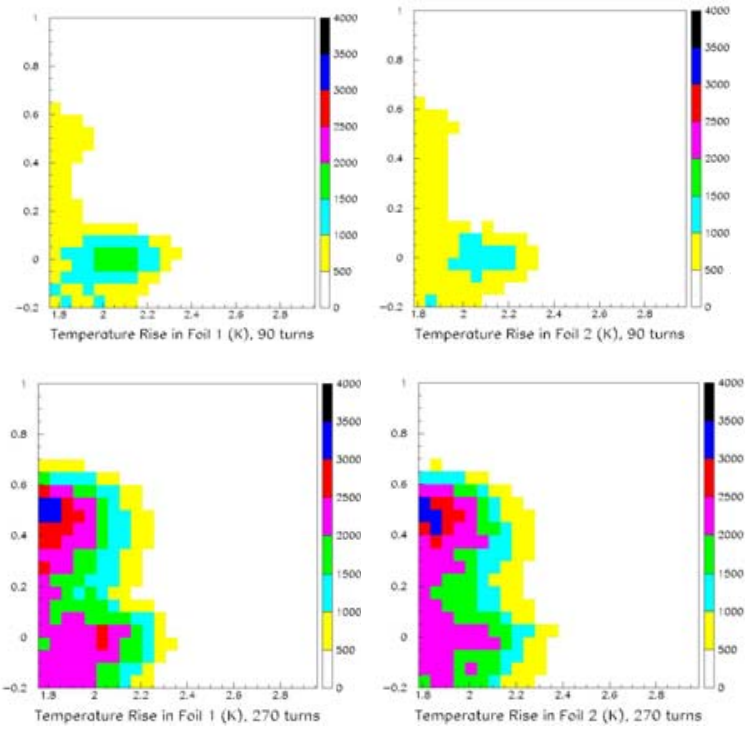

Figure 2: Temperature distribution from MARS: top - 90turn injection, bottom - 270-turn injection, left - first foil, right - second foil.

\section{Thermal and Mechanical Analysis using ANSYS}

The thermal process is governed by diffusion. In the carbon foil, it propagates at $0.174 \mathrm{~cm}^{2} / \mathrm{s}$. During $1 \mathrm{~ms} \mathrm{(3}$ $\mathrm{ms})$ beam pulse, the diffusion length is $0.0132 \mathrm{~cm}(0.0228$ $\mathrm{cm})$, much smaller than the foil size. The mechanical process propagates with speed of sound, which is 2558 $\mathrm{m} / \mathrm{s}$ in carbon. During $1 \mathrm{~ms}$ (3 ms) beam pulse, the mechanical disturbance propagates $255.8 \mathrm{~cm}(767.4 \mathrm{~cm})$, much larger than the foil size. Therefore, as far as the thermal process is concerned, energy deposition can be considered instantaneous. But it is static as far as the mechanical process is concerned.

A finite element model of ANSYS was built to simulate the problem. The model was supported on top and right sides (both thermally and mechanically).

In thermal analysis, both initial and boundary conditions were $275 \mathrm{~K}$. Energy deposition was input as heat rate (energy divided by time). Since it occurred on a time scale which was very small compared to heat diffusion, energy deposition was instantaneous. The temperature increase of the carbon foil was calculated as the integration of energy deposition over density and specific heat. After the pulse, in a period of 1.5 second there was no energy deposition. Heat would then be taken out by thermal radiation. Figure 3 is a typical temperature history at the hot spot. The temperature cycle reached equilibrium quickly (in two or three cycles).

Since the mechanical process could be considered static, the only load was the thermal stress induced in the foil. Using the maximum temperature from thermal analysis, the static displacement and stress were calculated. These results are summarized in Table 3. (Note: There is some difference in maximum temperature between Table 2 and 3. This is attributed to the different algorithm used in the codes MARS and ANSYS.) As an 
example, mechanical displacement and stress are plotted in Figure 4 for Foil 1 at 90-turn injection.

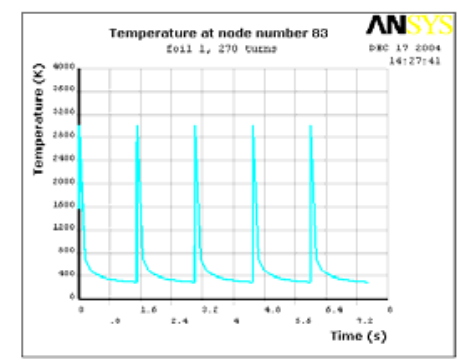

Figure 3: Temperature history at the center of the foil.

Table 3: Temperature Rise, Displacement and Stress (ANSYS)

\begin{tabular}{|c|c|c|c|c|}
\hline & $\begin{array}{l}\text { Foil } 1 \\
\text { 90-turn }\end{array}$ & $\begin{array}{l}\text { Foil } 1 \\
270 \text {-turn }\end{array}$ & $\begin{array}{l}\text { Foil } 2 \\
90 \text {-turn }\end{array}$ & $\begin{array}{l}\text { Foil } 2 \\
\text { 270-turn }\end{array}$ \\
\hline $\begin{array}{l}\text { Max T } \\
\text { (K) }\end{array}$ & 2084 & 3011 & 1675 & 2985 \\
\hline $\begin{array}{l}\text { Displace. } \\
(\mathrm{mm})\end{array}$ & $\begin{array}{l}-0.0218 \\
0.0090\end{array}$ & $\begin{array}{l}-0.0501 \\
0.0235\end{array}$ & $\begin{array}{l}-0.0168 \\
0.0078\end{array}$ & $\begin{array}{l}-0.0498 \\
0.0224\end{array}$ \\
\hline $\begin{array}{l}\text { Displace. } \\
(\mathrm{mm})\end{array}$ & $\begin{array}{l}-0.0263 \\
0.0067\end{array}$ & $\begin{array}{l}-0.0838 \\
0.0193\end{array}$ & $\begin{array}{l}-0.0243 \\
0.0063\end{array}$ & $\begin{array}{l}-0.0839 \\
0.0192 \\
\end{array}$ \\
\hline $\begin{array}{l}\text { Stress } \\
\left(\mathrm{N} / \mathrm{cm}^{2}\right)\end{array}$ & $\begin{array}{l}-7331 \\
6145 \\
\end{array}$ & $\begin{array}{l}-7744 \\
3873 \\
\end{array}$ & $\begin{array}{l}-5329 \\
2679 \\
\end{array}$ & $\begin{array}{l}-6965 \\
4142 \\
\end{array}$ \\
\hline $\begin{array}{l}\text { Stress } \\
\left(\mathrm{N} / \mathrm{cm}^{2}\right)\end{array}$ & $\begin{array}{l}-4390 \\
2887 \\
\end{array}$ & $\begin{array}{l}-12418 \\
3219 \\
\end{array}$ & $\begin{array}{l}-4010 \\
2397 \\
\end{array}$ & $\begin{array}{l}-11896 \\
4916 \\
\end{array}$ \\
\hline
\end{tabular}

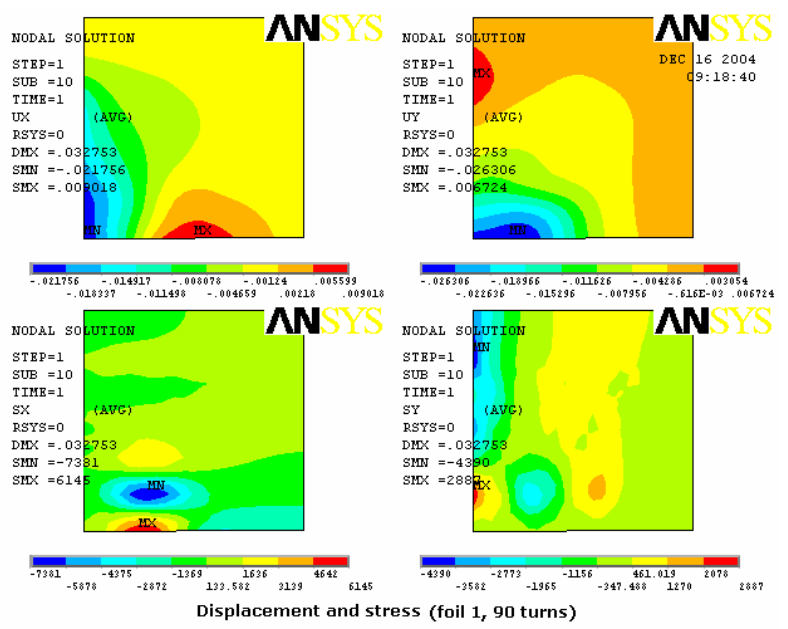

Figure 4: Displacement and stress of Foil 1 at 90-turn injection.

Buckling analysis was performed on a model representing one quarter of the foil. The results are shown in Figure 5. The maximum displacement was $0.038 \mathrm{~cm}$, which was significant and more than 100 times as large as the foil thickness.

\section{Carbon Foil Lifetime}

There are a number of factors that have impact on the lifetime of carbon foils: instant temperature rise, average temperature rise, mechanical stress and displacement, fatigue due to thermal buckling, sublimation (solid to gas transition at temperatures above $1600{ }^{\circ} \mathrm{C}$ ), radiation damage of the structure, etc. Although we know how to estimate these effects either analytically or numerically, it is not clear which one is the determining factor. It is quite likely that the failure of a carbon foil is a combinational result of several or all of these factors. Furthermore, foil manufacturing technique and foil microstructure play a major role in lifetime. For the same ion bombardment, different types of foils can have vastly different lifetime. Therefore, it seems that beam test in an accelerator is the only reliable way to determine the lifetime of a carbon foil.

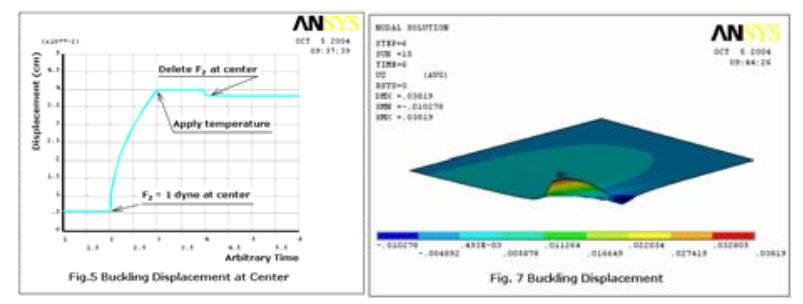

Figure 5: Left - buckling displacement at foil center, right - 3-D plot of buckling displacement (one quarter of foil).

\section{REFERENCES}

[1] http://tdserver1.fnal.gov/project/8GeVLinac DesignStudy/

[2] G.H. Gillespie, Phys. Rev. A 15, 563 (1977).

[3] G.H. Gillespie, Phys. Rev. A 16, 943 (1977).

[4] G.H. Gillespie, Nucl. Intr. \& Meth. B 2, 231 (1984).

[5] G.H. Gillespie, Nucl. Intr. \& Meth. B 10/11, 23 (1985).

[6] A.H. Mohagheghi et al., Phys. Rev. A $\underline{43}, 1345$ (1991).

[7] M.S. Gulley et al., Phys. Rev. A 53, 3201 (1996).

[8] R.C. Webber and C. Hojvat, IEEE Trans. NS $\underline{26}$, 4012 (1979).

[9] B. Gervais et al., Phys. Rev. A $\underline{53}, 3189$ (1996).

[10] P. Kurpick et al., Phys. Rev. A $\underline{58}, 2183$ (1998).

[11] P.B. Keating et al., Phys. Rev. A $\underline{58}, 4526$ (1998).

[12] S. Eidelman et al., Phys. Lett. B 592, 1 (2004).

[13]ESTAR program on the NIST web site: http://physics.nist.gov/PhysRefData/Star/Text/ESTA R.html

[14]A. Drozhdin and N. Mokhov, "The STRUCT program: User's reference manual," http://wwwap.fnal.gov/ drozhdin/STRUCT/

[15] N.V. Mokhov et al., "Recent enhancements to the MARS15 code", FERMILAB-Conf-04/053-AD, April 2004, presented at the 10th International Conference on Radiation Shielding, Funchal (Madeira), Portugal, May 9-14, 2004. e-Print Archive: nucl-th/0404084. http://wwwap.fnal.gov/MARS/. 